\title{
PENGEMBANGAN MODEL PEMBELAJARAN MATEMATIKA SMP BERBASIS BUDAYA DAERAH MELAYU SUMATERA UTARA
}

\author{
Edy Surya \\ E-mail : edy_surya71@yahoo.com \\ Dosen Matematika FMIPA Unimed Medan
}

\begin{abstract}
Abstrak
Kurangnya penggunaan teknologi dalam pembelajaran matematika dan minimnya pengintegrasian materi matematika terhadap nilai-nilai budaya lokal belum dapat menciptakan manusia intelektual dan bermoral kebangsaan, maka dibutuhkan solusi untuk memecahkan masalah.Penggunaan teknologi dalam dunia pendidikan merupakan keharusan untuk meningkatkan kualitas pembelajaran. Penelitian ini dilakukan di SMP Kota Medan dan Deli Serdang. Metode penelitian yang digunakan adalah penelitian pengembangan. Hasil penelitian dapat tersusun buku siswa, Buku guru, dan LAS, perangkat tes yang sesuaian dengan model Pembelajaran Matematika Berkonteks Budaya Daerah Sumatera Utara Terintegrasi dengan teknologi untuk melihat aktivitas siswa dan guru dalam mengajar matematika siswa SMP.
\end{abstract}

Kata Kunci : pembelajaran matematika, budaya derah, teknologi

\section{PENDAHULUAN}

\section{Latar Belakang Masalah}

Pada abad ke-21, dikenal dengan era globalisasi yang memiliki ciri perubahan antara lain: 1. perubahan dalam kehidupan masyarakat yang sangat cepat, 2. perkembangan teknologi yang sangat cepat yang berdampak pada gaya hidup dan pola tingkah laku masyarakat suatu bangsa. Hal ini mendorong terjadinya perubahan diberbagai sektor, tak terkecuali sektor pendidikan. Sistem pembelajaranpun mengalamai perubahan paradigma, yaitu dari paradikma yang berpusat pada mengajar menjadi berpusat pada belajar. Dimana paradikma yang berpusat pada belajar berorientasi pada pencapaian tujuan dalam rangka mempersiapkan siswa agar mampu belajar secara mandiri. Oleh karena itu perlu untuk melakukan perubahanperubahan strategi pembelajaran, pendekatan pembelajaran, dan teknologi pembelajaran. Gersnet menyatakan (Supriadi, 2001:4) 'Peran guru pada abad ke-21 adalah teacher as learners, who always improve and renew their knowledge. Guru harus mampu menciptakan suasana belajar mandiri. Hal tersebut dapat dilakukan dengan mengintegrasikan teknologi dalam proses pembelajaran.

Penggunaan teknologi dalam dunia pendidikan merupakan keharusan untuk meningkatkan kualitas pembelajaran. Dengan menggunakan teknologi seorang guru akan lebih mudah mengelola pembelajaran. Pengertian pembelajaran berbasis teknologi pada

Edy Surya. 2015. Pengembangan Model Pembelajaran Matematika SMP Berbasis Budaya Melayu Daerah Sumatera Utara. Inspiratif. Vol. 1 No. 1, hal. 83-95 
dasarnya adalah pembelajaran yang menggunakan teknologi sebagai media untuk mentransfer ilmu dari pendidik seorang guru dan peserta didik dituntut untuk melek teknologi. Karena untuk mendukung setiap proses pembelajaran selalu memanfaatkan teknologi.

sarat dengan intelektualistik dan materialistik, yang mengesampingkan nilai-nilai budaya lokal dan budi pekerti yang membentuk karakter siswa, sehingga produk pendidikan tersebut menghasilkan manusia yang pintar akan tetapi gagal menciptakan manusia yang bermoral dan berbudaya kebangsaan. Selama ini, pendidikan di Indonesia hanya sekedar ajang transfer ilmu pengetahuan. Padahal hakikat sesungguhnya pendidikan adalah proses transfer ilmu pengetahuan (transfer of knowledge) sekaligus juga mentransfes nilai (transfer of value). Penanaman nilai-nilai budaya lokal dalam pendidikan merupakan pondasi penyangga demi tegaknya bangsa yang kuat dan bermartabat. Oleh karena itu, persoalan teknologi dan budaya bangsa sudah menjadi permasalahan dalam keluarga, sekolah, daerah, bahkan nasional

\section{Berdasarkan masalah kurangnya penggunaan teknologi dalam pembelajaran matematika dan minimnya pengintegrasian materi matematika terhadap nilai-nilai budaya lokal guna menciptakan manusia intelektual dan bermoral kebangsaan, maka dibutuhkan solusi untuk memecahkan masalah tersebut. Untuk menyelesaikan permasalahan ini, perlu diciptakan konsep pendidikan yang mampu mencetak generasi muda yang memiliki intelektual dan bermoral sesuai budaya bangsa.}

adalah kepada peserta didik. Pembelajaran berbasis teknologi,

a. Dapat tersusun dan mengembangkan buku model Pembelajaran Matematika Berkonteks Budaya Daerah Sumatera Utara Terintegrasi dengan Teknologi.

b. Dapat menyusun dan mengembangkan perangkat pembelajaran (buku siswa, Buku guru, dan LAS) yang sesuai dengan model Pembelajaran Matematika Berkonteks Budaya Daerah Sumatera Utara terintegarasi Teknologi untuk dipergunakan guru dan siswa pada saat proses belajar mengajar matemtika siswa SMP.

c. Dapat tersusun dan mengembangkan perangkat tes yang sesuaian dengan model Pembelajaran Matematika Berkonteks Budaya Daerah Sumatera Utara Terintegrasi dengan teknologi untuk melihat aktivitas siswa dan guru dalam mengajar matematika siswa SMP.

\section{Metode Penelitian}

\section{Tempat dan waktu penelitian}

Penelitian ini dilakukan di SMP

Kota Medan dan Deli Serdang dilaksanakan sejak Januari tahun 2014 sampai Desember 2014

\section{Metode}

digunakan adalah penelitian pengembangan. Penelitian pengembangan berorientasi pada produk yang dilakukan dengan proses pengembangan yang sangat teliti dan hasil akhir akan dievaluasi (Richey dan Nelson, 1996).Untuk implementasi optimalisasi kulitas dari sebuah produk dalam situasi tertentu maka penelitian

Edy Surya. 2015. Pengembangan Model Pembelajaran Matematika SMP Berbasis Budaya Melayu Daerah Sumatera Utara. Inspiratif. Vol. 1 No. 1, hal. 83-95 
dilakukan secara penelitian formatif yaitu aktivitas penelitian dilakukan dalam proses berulang (cyclic) (Van den Akker, 1999).

Tahap pertama penelitian ini disebut Tahap Analisis Awal-Akhir (front-end analysis) untuk menganalisis dan menentukan kompetensi matematika yang harus dimiliki siswa dengan mempertimbangkan Kurikulum 2013 yang dirancang oleh PUSKUR Kemendiknas. Berikutnya tim ahli melakukan aktivitas pembuatan model pembelajaran matematika yang dirancang berdasarkan: (1) Teknologi, dalam hal ini teknologi yang digunakan komputer menggunakan perangkat lunak Geogebra
5.0, yang dapat mengaplikasikan matematika dari aljabar dan geometri., (2) budaya daerah Sumatera Utara. Model Awal pembelajaran matematika SMP Kelas VII akan dievaluasi dan dianalisis oleh tim ahli pendidikan dan guru-guru SMP yang berkompeten. Pakar-pakar dalam pengembangan kurikulum pendidikan matematika dari Kemendiknas Propinsi Sumatera Utara dan pakar pembelajaran Matematika dari Universitas Negeri Medan akan dilibatkan dalam penelitian ini. Jangka waktu kegiatan tahap awal dilaksanakan selama 6 bulan pertama penelitian.

- Analisis kompetensi matematika berdasarkan kurikulum 2013

- Analisis budaya daerah Sumatera

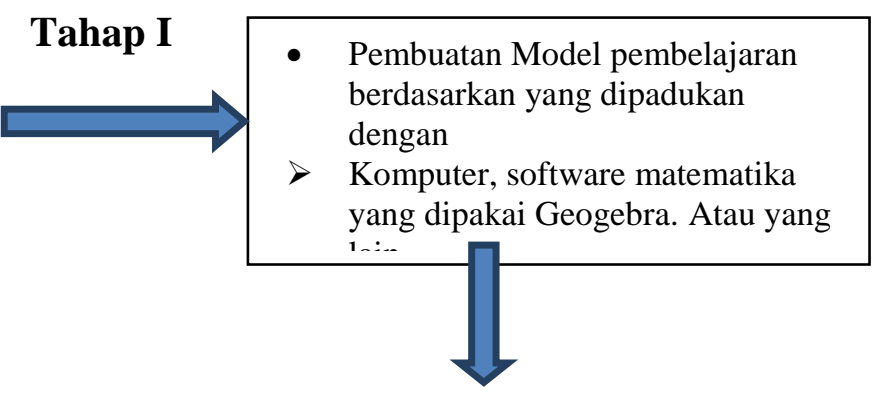

Model Awal pembelajaran

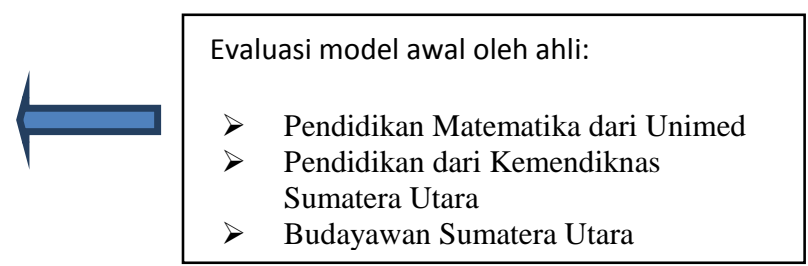

Gambar 1 Tahap analisis kompetensi, tujuan pembelajaran, Pembuatan Modul Awal

Edy Surya. 2015. Pengembangan Model Pembelajaran Matematika SMP Berbasis Budaya Melayu Daerah Sumatera Utara. Inspiratif. Vol. 1 No. 1, hal. 83-95 
Sementara itu gambar1 menggambarkan proses pengembangan menunjukkan diagram tulang ikan model pembelajaran dan target capaian (fishbone diagram) yang yang diinginkan.

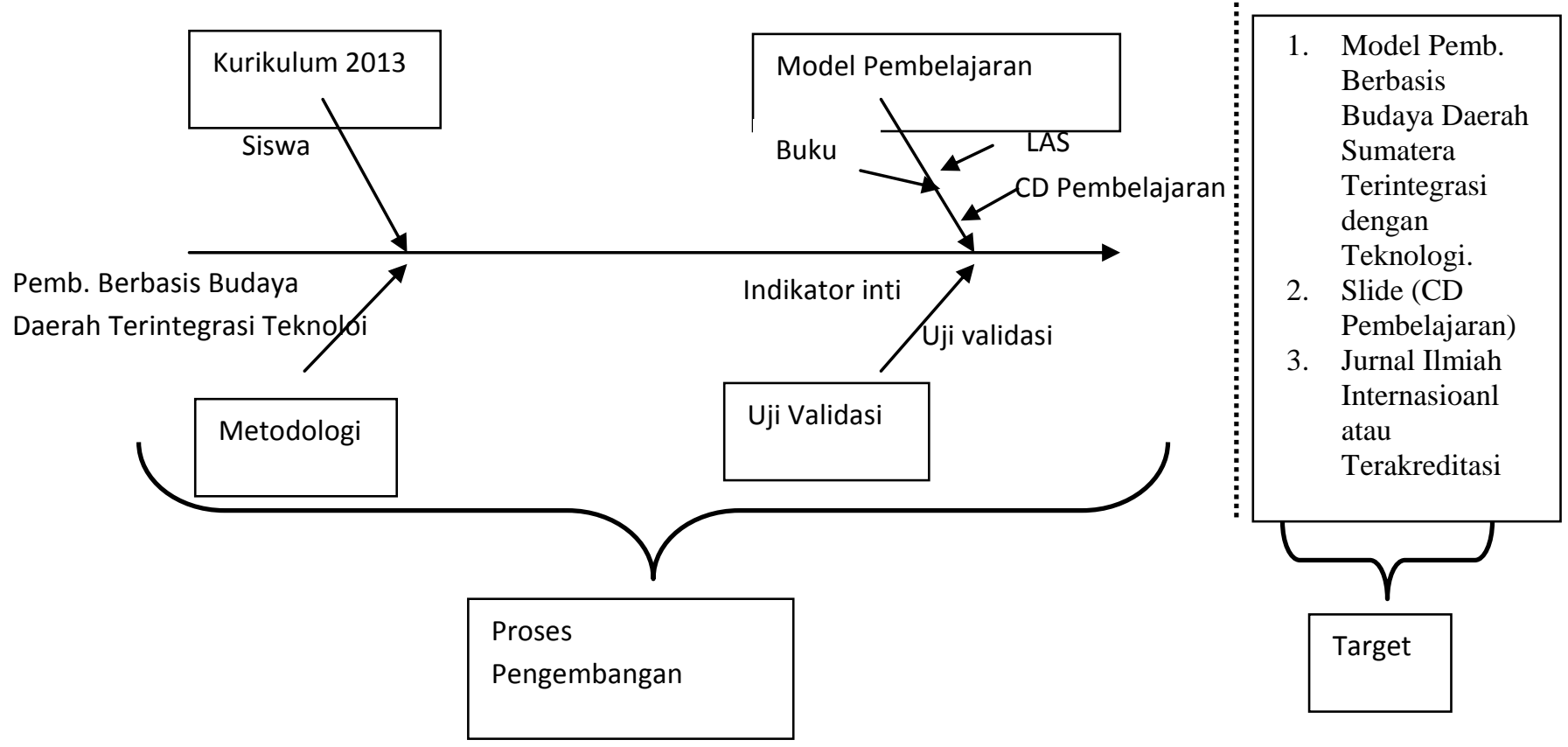

Gambar 2 fishbone diagram

Edy Surya. 2015. Pengembangan Model Pembelajaran Matematika SMP Berbasis Budaya Melayu Daerah Sumatera Utara. Inspiratif. Vol. 1 No. 1, hal. 83-95 


\section{Subjek Penelitian}

Subjek penelitan ini terdiri dari:

1. Guru-guru SMP/MTs negeri dan swasta di Sumatera Utara (Kabupaten Deli Serdang dan Kota Medan)

2. Siswa-siswi SMP/MTs negeri dan swasta di Sumatera Utara
(Kabupaten Deli Serdang dan Kota Medan)

3. Instansi terkait yaitu Kemendiknas Sumatera Utara.

Secara ringkas peta jalan penelitian ini ditunjukkan pada tabel 3 .

Tabel 3. Peta Jalan Penelitian Pengembangan Model Pembelajaran Berbasis Budaya Daerah Terintegrasi Teknologi

\begin{tabular}{|c|c|c|c|c|}
\hline & & Produk & & \\
\hline Sudah dilaksanakan & Akan dilaksanakan & Model Pembelajaran & $\begin{array}{l}\text { Dimuat dalam } \\
\text { Jurnal Terakreditasi }\end{array}$ & Bahan Ajar \\
\hline $\begin{array}{ll}\text { 1. } & \text { Kajian kurikulum } 2013 \\
\text { 2. } & \text { Kajian budaya daerah } \\
\text { 3. } & \text { Kajatera Utara teori belajar } \\
\text { 4. } & \text { Kajian teknologi berupa } \\
\text { software yang } \\
\text { dipergunakan } \\
\text { Hasil Kajian: } \\
\text { 1. } \\
\text { Permendiknas nomor } \\
\text { 22/2006 mengenai standar } \\
\text { isi/prinsip pelaksanaan } \\
\text { kurikulum } \\
\text { Budaya yang akan } \\
\text { dipergunakan adalah } \\
\text { budaya Melayu, Batak dan } \\
\text { perpaduan keduanya. } \\
\text { Teori belajar yang } \\
\text { dipergunakan adalah teori } \\
\text { belajar yang sesuai dengan } \\
\text { tingkat kognitif siswa, } \\
\text { budaya daerah dan } \\
\text { teknologi. } \\
\text { Goegebra merupakan } \\
\text { software yang tepat } \\
\text { dipergunakan untuk } \\
\text { peneltian ini sebab } \\
\text { geogebra software yang } \\
\text { dapat diunuh secara gratis } \\
\text { serta menggunakan } \\
\text { multibahas termasuk bahas } \\
\text { Indonesia }\end{array}$ &  & laktis, ped dgeogik & $\begin{array}{l}\text { 1. Makalah } \\
\text { Didaktis, pe } \\
\text { dan budaya }\end{array}$ & $\begin{array}{ll}\text { 1. } & \text { Buku } \\
\text { matematika } & \text { SMP } \\
\text { berbasis } \\
\text { seogid udaya } \\
\text { daerah } \\
\text { terintegrasi } \\
\text { teknologi } \\
\text { 2. CD } \\
\text { pembelajara } \\
\text { n }\end{array}$ \\
\hline
\end{tabular}

Edy Surya. 2015. Pengembangan Model Pembelajaran Matematika SMP Berbasis Budaya Melayu Daerah Sumatera Utara. Inspiratif. Vol. 1 No. 1, hal. 83-95 


\section{Pembahasan}

\begin{abstract}
Kekayaan budaya ini tentu dapat dijadikan sebagai suplemen dalam pembelajaran matematika. Pengetahuan dan pemahaman matematika itu hendaknya dibentuk dari mulai melakukan pemecahan masalah yang terjadi dalam kehidupan sehari-hari. Kompetensi matematika (menarik kesimpulan, mengkomunikasikan ide, memecahkan masalah, dan menyusun model) dapat dibentuk dari budaya yang ada disekitar siswa.
\end{abstract}

Perkembangan zaman saat ini berbanding lurus dengan kemajuan teknologi yang cukup pesat. Kehadiran dan kemajuan teknologi di era globalisasi ini memberikan peluang interaksi antara guru dan siswa, siswa dan siswa serta siswa dan sumber belajar lainnya dapat terjadi kapan saja dan dimana saja tanpa batas ruang dan waktu. Dengan teknologi proses penyampaian dan penyajian materi serta ide lebih menarik.Dilain pihak kehadiran teknologi memberikan tantangan baru kepada guru untuk menguasainya sehingga dapat memanfaatkan teknologi secara efektif dalam pembelajaran.Dari hasil survey yang dilakukan peneliti, dari $90 \%$ siswa tingkat SMP sudah sadar teknologi. Pada umumnya siswa SMP di Sumatera Utara sudah dapat mengoperasikan komputer. Namun penggunaan komputer untukmenunjang pembelajaran matematika masih sangat minim. Sebagian besar guru dan siswa tidak dapat menerapkan softwareinteraktif yang ada sebagi media pembelajaran matematika.Teknologi komputer masih sebatas digunakan untuk jejaring sosial.
Beranjak dari permasalahan inilah kerangka pengembangan model pembelajaran matematika berkonteks budaya daerah Sumatera Utara terintegrasi dengan teknologi disusun. Desentralisisi pendidikan dimanfaatkan sebagai upaya memperbaiki kualitas pendidikan baik dari segi kualitas maupun kuantitas. Oleh karena itu pengembangan model pembelajaran matematika berkonteks budaya daerah Sumatera Utara terintegrasi dengan teknologi sangat diperlukan guna memperkaya pengetahuan matematika siswa serta mendekatkan siswa dengan lingkungannya. Pengembangan model pembelajaran ini melibatkan guru dan para ahli pendidikan matematika di Sumatera Utara sehingga diharapkan dapat menghasilkan alur dan strategi pembelajaran yang berkualitas sesuai dengan kondisi Sumatera Utara.

\section{Hasil Penelitian}

Perangkat pembelajaran dan instrumen divalidasikan terlebih dahulu sebelum digunakan penelitian.Validasi terhadap perangkat pembelajaran dan instrumen bertujuna untuk memperoleh perangkat pembelajaran dan instrumen yang sahih dan layak digunakan dalam penelitian.Perangkat pembelajaran yang digunakan dalam penelitian ini adalah Rencana Pelaksanaan Pembelajaran (RPP) dan Lembar Aktivitas Siswa (LAS).Hasil validasi perangkat pembelajaran tersebut terlampir, sedangkan rangkumannya disajikan pada tabel 4.sebagai berikut : 
Tabel 4 Rata-rata dan Kategori Hasil Validasi Perangkat Pembelajaran

\begin{tabular}{|c|l|c|c|}
\hline No & \multicolumn{1}{|c|}{ Perangkat Pembelajaran } & Nilai Rata-Rata & Kategori \\
\hline 1. & Rencana Pelaksanaan Pembelajaran (RPP) & 4,28 & Baik \\
\hline 2. & Lembar Aktivitas Siswa (LAS) & 4,26 & Baik \\
\hline
\end{tabular}

\begin{abstract}
Berdasarkan hasil validasi perangkat pembelajaran tersebut diperoleh bahwa semua perangkat pembelajaran tersebut baik untuk digunakan dalam pembelajaran.Instrumen dalam penelitian terdiri dari tes kemampuan spasial
\end{abstract}

siswa.Hasil validasi instrumen tersebut dapat dilihat pada lampiran sedangkan rangkumannya disajikan pada tabel 5 sebagai berikut :

Tabel 5. Hasil Validasi Tes Kemampuan Keruangan

\begin{tabular}{|c|c|c|c|c|c|c|c|c|c|c|c|c|c|c|}
\hline \multirow{2}{*}{ No } & \multirow{2}{*}{$\begin{array}{c}\text { Nama } \\
\text { Validator }\end{array}$} & \multicolumn{13}{|c|}{ Penilaian Validator untuk Setiap Butir Soal } \\
\hline & & $\mathbf{1 a}$ & 1b & 2 & 3 & $4 \mathbf{a}$ & $4 \mathbf{b}$ & $4 \mathrm{c}$ & $\mathbf{5 a}$ & $\mathbf{5 b}$ & $5 c$ & $\mathbf{6 a}$ & $\mathbf{6 b}$ & 6c \\
\hline 1. & Validatir 1 & TR & TR & RK & TR & RK & TR & RK & TR & RK & RK & TR & TR & TR \\
\hline 2. & Validatir 2 & TR & TR & RK & TR & TR & RK & RK & TR & TR & TR & RK & RK & TR \\
\hline 3. & Validatir 3 & TR & TR & TR & TR & TR & TR & TR & TR & $\mathrm{Rk}$ & TR & TR & TR & TR \\
\hline 4. & Validatir 4 & RK & TR & TR & RK & TR & RK & TR & TR & TR & TR & TR & RK & TR \\
\hline 5. & Validatir 5 & TR & TR & RK & TR & RK & TR & TR & TR & TR & TR & TR & RK & TR \\
\hline
\end{tabular}

Hasil validasi instrumen tersebut menunjukkan bahwa tes kemampuan spasial (keruangan) siswa dalam penelitian ini dapat digunakan untuk mengukur kemampuan spasial siswa dengan revisi kecil atau sedikit revisi.

\subsubsection{Hasil Uji Coba Perangkat Pembelajaran dan Instrumen}

Setelah dilakukan validasi, perangkat pembelajaran dan instrumen yang digunakan telah diujicobakan sebelum digunakan dalam penelitian. Perangkat pembelajaran yang digunakan adalah Rencana Pelaksanaan Pembelajaran (RPP) dan Lembar Aktivitas Siswa (LAS). RPP yang diujicobakan adalah RPP 1. RPP tersebut menerapkan pembelajaran kooperatif tipe STAD untuk meningkatan kemampuan spasial siswa pada budaya makan sirih (tepak sirih) yakni medianya berupa bangun geometri balok/kotak pada sub materi kubus dan balok di kelas VIII.Selanjutnya, LAS yang diujicobakan adalah LAS I. LAS tersebut mendukung pembelajaran kooperatif tipe STAD untuk meningkatkan kemampuan spasial siswa pada materi geometri dengan sub materi kubus dan balok di kelas VIII.

Instrumen yang digunakan dalam penelitian ini adalah tes kemampuan awal, tes kemampuan keruangan siswa. Tes kemampuan keruangan terdiri dari pretes dan postes.Hasil uji coba

Edy Surya. 2015. Pengembangan Model Pembelajaran Matematika SMP Berbasis Budaya Melayu Daerah Sumatera Utara. Inspiratif. Vol. 1 No. 1, hal. 83-95 
instrumen ini juga hasilnya dapat dikatakan baik.

Uji coba instrumen tersebut juga bertujuan untuk mengetahui reliabilitas, validitas butir soal, daya pembeda soal, dan tingkat kesukaran butir soal instrumen.Reliabitas, validitas butir soal, daya pembeda soal, dan tingkat kesukaran butir soal kemampuan awal matematika tersebut baik,

Tabel 6. Reliabilitas, Validasi Butir Soal, Daya Pembeda Butir Soal, dan Tingkat Kesukaran Butir Soal Kemampuan Awal Matematika

\begin{tabular}{|c|c|c|c|c|c|c|c|}
\hline \multirow{2}{*}{$\begin{array}{c}\text { Nomor } \\
\text { Soal }\end{array}$} & \multicolumn{3}{|c|}{ Validasi Butir Soal } & \multicolumn{2}{|c|}{ Daya Pembeda } & \multicolumn{2}{|c|}{$\begin{array}{c}\text { Kesukaran } \\
\text { Soal }\end{array}$} \\
\hline & $r$ & Keterangan & Interpretasi & $D$ & Kriteria & $I$ & Kriteria \\
\hline 1 & 0,747 & Valid & Kuat & 0,9 & Baik Sekali & 0,5 & Mudah \\
\hline 2 & 0,678 & Valid & Kuat & 0,8 & Baik Sekali & 0,5 & Mudah \\
\hline 3 & 0,624 & Valid & Kuat & 0,6 & Baik & 0,6 & Mudah \\
\hline 4 & 0,000 & Tidak Valid & Tidak Interpretasi & 0 & Jelek & 0 & Sukar \\
\hline 5 & 0,674 & Valid & Kuat & 0,7 & Baik & 0,4 & Mudah \\
\hline 6 & 0,718 & Valid & Kuat & 1 & Cukup & 0,4 & Mudah \\
\hline 7 & 0,727 & Valid & Kuat & 0,9 & Baik Sekali & 0,5 & Mudah \\
\hline 8 & 0,747 & Valid & Kuat & 0,9 & Baik Sekali & 0,5 & Mudah \\
\hline 9 & $-0,086$ & Tidak Valid & Tidak Interpretasi & 0 & Jelek & 0,1 & Sukar \\
\hline 10 & 0,709 & Valid & Kuat & 1 & Baik Sekali & 0,4 & Mudah \\
\hline 11 & 0,000 & Tidak Valid & Tidak Interpretasi & 0 & Jelek & 0 & Sukar \\
\hline 12 & 0,397 & Valid & Rendah & 0,5 & Baik & 0,6 & Mudah \\
\hline 13 & 0,397 & Valid & Rendah & 0,5 & Baik & 0,6 & Mudah \\
\hline 14 & 0,000 & Tidak Valid & Tidak Interpretasi & 0 & Jelek & 0 & Sukar \\
\hline 15 & 0,504 & Valid & Sedang & 0,6 & Baik & 0,7 & Mudah \\
\hline 16 & 0,674 & Valid & Kuat & 0,7 & Baik & 0,4 & Mudah \\
\hline 17 & 0,704 & Valid & Kuat & 0,9 & Baik Sekali & 0,5 & Mudah \\
\hline 18 & 0,709 & Valid & Kuat & 1 & Baik Sekali & 0,4 & Mudah \\
\hline 19 & 0,709 & Valid & Kuat & 1 & Baik Sekali & 0,4 & Mudah \\
\hline 20 & 0,397 & Valid & Rendah & 0,5 & Baik & 0,6 & Mudah \\
\hline
\end{tabular}

Edy Surya. 2015. Pengembangan Model Pembelajaran Matematika SMP Berbasis Budaya Melayu Daerah Sumatera Utara. Inspiratif. Vol. 1 No. 1, hal. 83-95 


\begin{tabular}{|c|c|c|c|c|c|c|c|}
\hline 21 & 0,621 & Valid & Kuat & 0,7 & Baik & 0,4 & Mudah \\
\hline 22 & 0,709 & Valid & Kuat & 1 & Baik Sekali & 0,4 & Mudah \\
\hline 23 & 0,504 & Valid & Sedang & 0,6 & Baik & 0,7 & Mudah \\
\hline 24 & 0,504 & Valid & Sedang & 0,6 & Baik & 0,7 & Mudah \\
\hline 25 & 0,114 & Tidak Valid & Sangat Rendah & 0 & Jelek & 0,1 & Sukar \\
\hline
\end{tabular}

\begin{tabular}{|c|c|}
\hline \multicolumn{2}{|c|}{ Reliabilitas } \\
\hline $\boldsymbol{r}_{\mathbf{1 1}}$ & 0,948 \\
\hline Kategori & sangat tinggi \\
\hline
\end{tabular}

Reliabitas, validitas butir soal, daya pembeda soal, dan tingkat kesukaran butir soal kemampuan spasial tersebut dapat dilihat pada lampiran 4-3, sedangkan rangkumannya disajikan pada tabel 7 sebagai berikut

Tabel 7. Reliabilitas, Validasi Butir Soal, Daya Pembeda Butir Soal, dan Tingkat Kesukaran Butir Soal Kemampuan Spasial

\begin{tabular}{|c|c|c|c|c|c|c|c|}
\hline \multirow{2}{*}{$\begin{array}{c}\text { Nomor } \\
\text { Soal }\end{array}$} & \multicolumn{3}{|c|}{ Validasi Butir Soal } & \multicolumn{2}{|c|}{ Daya Pembeda } & \multicolumn{2}{|c|}{ Kesukaran Soal } \\
\hline & $r$ & Keterangan & Interpretasi & $D$ & Kriteria & $I$ & Kriteria \\
\hline 1 & 0,627 & Valid & Kuat & 0,291 & Cukup & 0,424 & Sedang \\
\hline 2 & 0,477 & Valid & Sedang & 0,231 & Cukup & 0,833 & Mudah \\
\hline 3 & 0,495 & Valid & Sedang & 0,234 & Cukup & 0,8 & Mudah \\
\hline 4 & 0,866 & Valid & Kuat & 0,289 & Cukup & 0,5 & Sedang \\
\hline 5 & 0,915 & Valid & Kuat & 0,329 & Cukup & 0,516 & Sedang \\
\hline 6 & 0,839 & Valid & Kuat & 0,28 & Cukup & 0,478 & Sedang \\
\hline \multicolumn{8}{|c|}{ Reliabilitas } \\
\hline \multicolumn{2}{|c|}{$r_{11}$} & \multicolumn{6}{|c|}{0,772} \\
\hline \multicolumn{2}{|c|}{ Kategori } & \multicolumn{6}{|c|}{ cukup } \\
\hline
\end{tabular}

Edy Surya. 2015. Pengembangan Model Pembelajaran Matematika SMP Berbasis Budaya Melayu Daerah Sumatera Utara. Inspiratif. Vol. 1 No. 1, hal. 83-95 


\section{Analisis Hasil Tes Kemampuan Awal Matematika}

Setelah melaksanakan validasi dan uji coba perangkat pembelajaran dan instrumen penelitian, langkah selanjutnya adalah memberikan tes kemampuan awal matematika pada kelas eksperimen dan kelas kontrol sebagaimana terlampir pada lampiran 4.Tes tersebut bertujuan untuk mengetahui kemampuan awal matematika siswa sebelum dilaksanakannya pembelajaran.Tes tersebut juga bertujuan untuk mengelompokan siswa menjadi tiga kelompok, yaitu siswa berkemampuan tinggi, sedang, dan rendah. Berikut ini akan dijelaskan analisis hasil tes kemampuan awal matematika pada kelas eksperimen dan kelas kontrol.

\section{Perhitungan Rata-rata dan Simpangan Baku}

Perhitungan rata-rata dan simpangan bakunya

Tabel 8. Rata-rata dan Simpangan Baku Hasil Tes Kemampuan Awal Matematika pada Kelas Eksperimen dan Kelas Kontrol

\begin{tabular}{|c|c|c|c|c|c|}
\hline Kelompok & $\begin{array}{c}\text { Jumlah } \\
\text { Siswa }\end{array}$ & $\begin{array}{c}\text { Rata- } \\
\text { rata }\end{array}$ & $\begin{array}{c}\text { Simpangan } \\
\text { Baku }\end{array}$ & $\begin{array}{c}\text { Skor } \\
\text { Tertinggi }\end{array}$ & $\begin{array}{c}\text { Skor } \\
\text { Terendah }\end{array}$ \\
\hline Kelas Eksperimen & 39 & 9,231 & 3,759 & 16 & 2 \\
\hline Kelas Kontrol & 39 & 8,769 & 3,199 & 15 & 3 \\
\hline
\end{tabular}

Dari tabel 8 tersebut tampak bahwa perbedaan rata-rata hasil tes kemampuan awal pada kelas eksperimen dan kelas kontrol terlalu besar.Oleh sebab itu, perlu dilakukan pengujian perbedaan rata-rata untuk mengetahui apakah rata-rata hasil tes kemampuan awal matematika tersebut berbeda atau tidak dengan melakukan pengujian normalitas dan homogenitasnya terlebih dahulu.

Berdasarkan hasil ujicoba di sekolah SMP model pembelajaran, perangkat pembelajaran (RPP, LAS dan istrumen soal) dapat digunakan.

\section{KESIMPULAN DAN SARAN}

Kesimpulan pada penelitian ini adalah sebagai berikut :

1. Dapat digunakan dan terus dikembangan perangkat pembelajaran (buku siswa, Buku guru, dan LAS) yang sesuai dengan model Pembelajaran Matematika Berkonteks Budaya Daerah Melayu terintegarasi Teknologi software Wingeom untuk dipergunakan guru dan siswa pada saat proses belajar mengajar matemtika siswa SMP.

2. Perangkat tes yang dihasilkan sesuai dengan model Pembalajaran Matematika Berkonteks Budaya Melayu Terintegrasi dengan teknologi

Edy Surya. 2015. Pengembangan Model Pembelajaran Matematika SMP Berbasis Budaya Melayu Daerah Sumatera Utara. Inspiratif. Vol. 1 No. 1, hal. 83-95 
software Wingeom untuk melihat aktivitas siswa dan guru dalam mengajar matematika siswa SMP.

Saran pada tulisan ini adalah :

1. Diharapkan kepada siswa dan guru agar lebih terampil dalam menggunakan teknologi komputer. Guru harus mampu menciptakan suasana belajar

\section{DAFTAR PUSTAKA}

Armanto, Dian (2002). Teaching multiplication dan division realistically in Indonesian primary schools: A prototype of local instructional theory. Disertation. University of Twente, Enschede: PrintPartners Ipskamp.

Castro, d. B. (2004).Pre-Service Teachers' Mathematical Reasoning as an Imperative for Codified Conceptual Pedagogy in Algebra: A case Study in Teacher Education.[Online]. Tersedia: http://www.eric.ed.gov/ERICDocs/ data/ericdocs 2 sql/content_storage 01/0000019b/80/2a/25/a5.pdf. [10 Maret, 2013].

Cielos, P. R, dkk. (2010). Computer Algebra Systems: A basic tool for taching Mathematics in Engineering. [Online]. Tersedia: http://www.formatex.org/micte200 5/284.pdf. [15 Maret 2013] mandiri. Hal tersebut dapat dilakukan dengan menguasai teknologi dalam proses pembelajaran.

2. Bahan ajar dan instrumen lain yang dihasilkan masih perlu diujicobakan di sekolah-sekolah lain agar benar-benar diperoleh bahan ajar yang berkualitas.
Dikociv, L. (2009). Applications Geogebra into Teaching Some Topics of Mathematics at the College Level.ComSIS Vol 6, No. 2.

Fajar, Shadiq. (2004). Penalaran, Pemecahan Masalah dan Komunikasi dalam Pembelajaran Matematika. Makalah yang disajikan pada diklat Instruktur/Pengembang Matematika SMP Jenjang Dasar, tanggal 10 s.d 23 Oktober 2004, Depdiknas PPPG Matematika, Yogyakarta

Fatirul, N. A. (2008). Cooperative Learning.[Online]. Tersedia: http://trimanjuniarso.files.wordp ress.com/2008/02/c00perativelearning.pdf. [4 Maret 2013] 
Fink, L. Dee. 2003, Creating Significant Learning Eksperinces 9An Integrated Approach to Designing College Courses). San Fransisco: Jossey-Bass.

Fortis, A, dkk. (2011). Geogebra: Another way of looking Mathematics. Anale, Seria Informatica Vol. IX fasc. 22011. Tibiscus.

Hohenwarter, M, dkk.(2008). Teaching and Learning Calculus with Free Dynamic Mathematics Software Geogebra. TSG 16: Research and development in the teaching and learning of calculus. ICME 11, Monterrey, Mexico.

Hornes, P. H, dkk, (2009). Use of Computer Algebra Systems in Norwegian Engeneering Education.[Online]. Tersedia: http://www.ineer.org/Events/IC EE2001/Proceedings/papers/121 /pdf. [15 Maret 2013]

Krulik, S dan Rudnick, J.A (1995).The New Sourcebook for Teaching Reasoning and Problem Solving in Elementary School. Massachusetts: Allyn \& Bacon A Simon \& Schuster Company

Laviza, Z, Hohenwarter, M. (2009).The strength of the community: how Geogebra cin inspire technology integration in mathematics teaching. MSOR Connection Vol 9 No 2 May - July 2009.
Malone, John A., Douglas, Graham A., Kissane, Barry V., and Mortlock, Roland S. 1989.Measuring problem-solving ability. In New Directions for Elementary School Mathematics: 1989 Yearbook, edited by Paul R. Trafton and Albert P. Schulte. Reston, virginia: NCTM.

Priatna, N. (2003). Kemampuan Penalaran dan Pemahaman Matematik Siswa Kelas 3 Seklolah Lanjutan Tingkat Pertama Negeri di Kota Bandung.Disertasi Doktor Pada PPS UPI Bandung. Tidak diterbitkan

Sukmadinata, S. N, Alexon.(2010). Pengembangan Model Pembelajaran Terpadu Berbasis Budaya Untuk Meningkatkan Apresiasi Siswa Terhadap Budaya Lokal.Jurnal: Cakrawala Pendidikan, Juni 2010 No 2. UPI Perss.

Tika, K, Suastra, W. I. Kariasa, N. (2011). Efektivitas Model Pembelajaran Sains Berbasis Budaya Lokal Untuk Mengembangkan Kompetensi Dasar Sains dan Nilai Kearifan Lokal Di SMP. Jurnal Penelitian dana Pengambangan Pendidikan, JPPP Undiksa.

Widiarto.(2004).

[Online].Tersedia.http://p4tkmat ematika.org/downloads/ppp/. [4 Maret 2013]

Edy Surya. 2015. Pengembangan Model Pembelajaran Matematika SMP Berbasis Budaya Melayu Daerah Sumatera Utara. Inspiratif. Vol. 1 No. 1, hal. 83-95 
Yuniarti, Y. (2007). Meningkatkan Kemampuan Penalaran dan Komunikasi Matematik Siswa Sekolah Menengah Pertama Melalui Pembelajaran Dengan Pendekatan Inkuiri.Tesis Magister Pada SPS UPI Bandung.Tidak diterbitkan.

TIMSS. 1997. International versions of the background questionnaires. TIMSSInternationalStudyCenter: BostonCollege, Chestnut Hill, MA, June 1997.
Van den Akker, Jan. 1999. Principles and methods of development research.In Jan van den Akker et al. (Ed.) Design Approaches and Tools in Education and Training pp. 114.Dordrecht: kluwer Academic Publishe 
Edy Surya. 2015. Pengembangan Model Pembelajaran Matematika SMP Berbasis Budaya Melayu Daerah Sumatera Utara. Inspiratif. Vol. 1 No. 1, hal. 83-95 